\title{
Treatment of exudative age-related macular degeneration with anti-angiogenic drugs: analysis of long-term visual function in routine clinical practice
}

\section{Tratamiento con fármacos antiangiogénicos de la degeneración macular asociada a la edad exudativa: análisis de la función visual a largo plazo en la práctica clínica habitual}

\author{
Ana Palazón-Cabanes ${ }^{1 *}$, Begoña Palazón-Cabanes² and Inmaculada Sellés-Navarro ${ }^{1}$ \\ ${ }^{1}$ Ophthalmology Service, Reina Sofía General University Hospital; ${ }^{2}$ Neurology Service, Virgen de la Arrixaca University Hospital. Murcia, Spain
}

\begin{abstract}
Purpose: To analyze the long-term visual outcomes of vascular endothelial growth factor inhibitors in treatment-naïve eyes with neovascular age-related macular degeneration (AMD). Methods: Retrospective study with 48 eyes of 44 treatment-naïve patients with neovascular AMD treated only with anti-angiogenic. Visual acuity (VA) results were analyzed after 6 months and 1,3, and 5 years of follow-up. Results: Mean VA improved from 61.04 to 65.83 letters after 6 months, with a loss of -1.14 , -16.88 and -27.50 letters compared to baseline after 1, 3 and 5 years. The proportion of eyes that lost $<15$ letters at 3 and 5 years was $50 \%$ and $33.3 \%$, respectively. The proportion of eyes with a gain of $>15$ letters was $14.6 \%$ and $12.5 \%$ at 3 and 5 years. The proportion of eyes with a VA > 70 letters was $41.7 \%$ at baseline and $22.92 \%$ and $10.42 \%$ after 3 and 5 years. The mean number of injections received was 4.81, 2.21, 1.73, 1.17 and 0.9 at years 1, 2, 3, 4, and 5, respectively, and the mean number of visits was 7.19, 4.88, 4.02, 3.40, and 2.85. Older age, lower VA at baseline and pseudophakic eyes showed worse long-term visual outcomes. Conclusions: The visual outcomes of this study are inferior compared to previous studies. Nevertheless, the number of injections received was lower, and all eyes completed a 5-year follow-up.
\end{abstract}

Key words: Age-related macular degeneration. Endothelial growth factor inhibitors. Visual acuity. Visual function. Long-term outcomes.

\section{Resumen}

Objetivo: Analizar los resultados visuales a largo plazo de ojos con degeneración macular asociada a la edad exudativa (DMAE) tratados con inhibidores del factor de crecimiento endotelial en la práctica clínica real. Método: Estudio retrospectivo que incluye 48 ojos de 44 pacientes con DMAE húmeda, únicamente tratados con fármacos antiangiogénicos. Se analizaron los valores de agudeza visual (AV) tras 6 meses, y tras 1, 3 y 5 años de seguimiento. Resultados: La AV mejoró de 61.04 a 65.83 letras a los 6 meses, con una pérdida de -1.14, -16.88 y -27.50 letras respecto a la AV inicial a los 1 , 3 y 5 años, respectivamente. El porcentaje de ojos con una pérdida $<15$ letras fue del 50 y del $33.3 \%$ a los 3 y 5 años, respectivamente. Un $14.6 \%$ mejoró $\geq 15$ letras a los 3 años y un $12.5 \%$ a los 5 años. Los ojos con AV $\geq 70$ letras previo al tratamiento fueron el $41.7 \%$, descendiendo al $22.92 \%$ a los 3 años y a $10.42 \%$ a los 5 años. El número medio de inyecciones fue

Correspondence:

*Ana Palazón-Cabanes

Avda. Intendente Jorge Palacios, 1 Date of reception: 16-06-2019

C.P. 30003 Murcia, Spain

E-mail: a.palazoncabanes@gmail.com

DOI: 10.24875/RMOE.M20000125
Available online: 01-09-2020 Rev Mex Oftalmol (Eng). 2020;94(5):192-198

www.rmo.com.mx (http://creativecommons.org/licenses/by-nc-nd/4.0/). 
$4.81,2.21,1.73,1.17$ y 0.9 en el primer, segundo, tercer, cuarto y quinto años de seguimiento, respectivamente, con un número medio de visitas de 7.19, 4.88, 4.02, 3.40 y 2.85, respectivamente. La edad avanzada, la menor AV basal y la pseudofaquia presentaron resultados visuales menos satisfactorios a largo plazo. Conclusiones: Los resultados visuales de este estudio son inferiores a estudios previos. Sin embargo, el número de inyecciones recibidas fue menor y todos los ojos completaron un seguimiento de 5 años.

Palabras clave: Degeneración macular asociada a la edad. Inhibidores del factor de crecimiento endotelial. Agudeza visual. Función visual. Resultados a largo plazo.

\section{Introduction}

Age-related macular degeneration (AMD) is the leading cause of irreversible central visual loss and legal blindness among individuals over the age of 55 in developed countries, and it is estimated to affect more than 3 million people in the United States in 2020. The emergence of antiangiogenic drugs directed against vascular endothelial growth factor (VEGF) has brought a revolution in the treatment of exudative AMD1.

Bevacizumab (Avastin ${ }^{\circledR}$, Genentech) is a complete antibody molecule that recognizes and inhibits all isoforms of human VEGF-A. Its high molecular weight was thought to be a limitation for penetrating the retina ${ }^{2}$, and this promoted the development of a humanized Fab fragment of the same antibody: ranibizumab (Lucentis ${ }^{\circledR}$, Genentech), which was approved by the FDA (Food and Drug Administration) in 2006 as a result of the pivotal studies MARINA ${ }^{3}$ and $\mathrm{ANCHOR}^{4}$. Subsequently, the CATT $^{5}$ study demonstrated that the efficacy of ranibizumab and bevacizumab was equivalent in terms of VA.

Following these studies, the important question arose of how to achieve the greatest benefits in terms of visual gain and its maintenance with the fewest number of injections. To this end, studies with fixed-interval treatment regimens ${ }^{6,7}$ were designed but showed less favorable overall results compared to monthly regimens. Later, other studies evaluated the possible benefits of an on-demand regimen, called "Pro Re Nata" $(\mathrm{PRN})^{8-11}$, which consisted of an initial dose of three consecutive monthly injections of ranibizumab, followed by monthly visits and retreatments depending on the functional and/or structural criteria established in each of the studies. This regimen showed to maintain the efficacy of the treatment. Subsequently, a new system called «Treat and Extend» (T\&E) 12 was proposed, in which retreatment intervals were increased sequentially by 2 weeks up to a maximum of 12 weeks and, in case of recurrence of signs of exudation, the monitoring would start at narrower intervals to be gradually spaced out again. This regimen achieves a significant improvement in VA with fewer visits and injections compared to monthly protocols.
The last antiangiogenic introduced for the treatment of neovascular AMD is aflibercept (Eylea ${ }^{\circledR}$ Regeneron Pharmaceuticals Inc), with a capacity of binding to VEGF almost 100 times higher than ranibizumab and bevacizumab, and with an efficacy similar to ranibizumab, documented in two important clinical trials (VIEW 1 and VIEW 2) ${ }^{13,14}$, and requiring fewer injections.

\section{Material and methods}

Descriptive and retrospective study that collected data from a total of 48 eyes from 44 patients, including between 2008 and 2011, diagnosed with exudative AMD without prior ocular treatment and who began intravitreal antiangiogenic therapy after the diagnosis of macular disease. All patients completed a follow-up period of at least 5 years. VA values (ETDRS scale) at 6 months, 1,3 and 5 years of follow-up have been collected and studied. In addition, the evolution of visual function has been analyzed according to different clinical variables: Baseline VA prior to antiangiogenic treatment, demographic characteristics (age and sex), whether it was the first or second eye affected, or whether the eye studied was phakic or pseudophakic. Finally, documented VAs were compared at different times regarding each of these clinical variables.

\section{Results}

\section{Visual acuity}

Mean baseline VA was $61.04 \pm 2.26$ letters $(95 \% \mathrm{Cl}$ : 56.49-65.59). At 3 months of follow-up, an improvement in VA was observed to 66.15 letters (SD, 1.79 letters), which remained unchanged at 6 months of follow-up with an average of 65.83 letters (SD, 1.73 letters). However, mean VA suffered a progressive decrease in the following time points, with values of 59.90 letters (SD, 2.99 letters), 44.17 letters (SD, 3.88 letters) and 33.54 letters (SD, 3.89 letters) at 1,3 , and 5 years of follow-up, respectively. These data reveal a visual loss at the time of diagnosis of 16.88 letters (SD, 4.09 letters) and 27.50 
letters (SD, 4.36 letters), after a period of 3 and 5 years of antiangiogenic therapy, respectively (Fig. 1).

The eyes that suffered a loss of VA $>15$ letters, compared to initial VA, were $50 \%$ at 3 years and $66.7 \%$ at 5 years of follow-up, respectively. On the other hand, an improvement in VA of $>15$ letters was observed in 14.6 and $12.5 \%$ of cases at 3 and 5 years, respectively.

\section{Antiangiogenic therapy}

$45.8 \%$ of the cases were treated with a single type of drug: $13.6 \%$ only with bevacizumab and $86.4 \%$ only with ranibizumab. $54.2 \%$ of cases received more than one type of drug. Among the latter, bevacizumab was used in $48.37 \%$ of the injections, ranibizumab in $44.48 \%$ of the injections and aflibercept in $7.14 \%$ of the injections.

Table 1 shows the mean number of intravitreal injections of anti-VEGF drugs, as well as the average number of visits per year in each of the follow-up years.

\section{Evolution of visual acuity based on other clinical variables}

\section{BASELINE VISUAL ACUITY}

Patients with a VA at diagnosis $\geq 70$ letters (20/40) $(n=20)$ experienced a loss of 24.75 letters (SD, 6.37) and 39.25 letters (SD, 6.90) at 3 and 5 years of follow-up, respectively. The cases that initially had a vision $\leq 35$ letters $(20 / 200)(n=5)$ experienced an improvement of VA of 8 letters (SD, 7.00) at 3 years of follow-up. At 5 years, the balance was a loss of 4 letters compared to baseline VA in these eyes (Fig. 1).

The proportion of eyes that experienced a VA loss of $>15$ letters at 3 years of follow-up was of $55 \%$ for a baseline VA $\geq 70$ letters, $52.2 \%$ for those with $36-69$ letters and $20 \%$ for those with a VA of $\leq 35$ letters. At 5 years of follow-up, this proportion was $80,60.9$, and $40 \%$ for each of the groups, respectively. Eyes with good visual function at diagnosis ( $\geq 70$ letters) did not achieve a significant long-term visual gain (no cases showed an improvement $>15$ letters). In contrast, eyes with a poor initial vision ( $\leq 35$ letters) gained $>15$ letters in 60 and $20 \%$ at 3 and 5 years, respectively.

The eyes that read more letters at the onset of choroidal neovascularization maintained a higher VA compared to the other cases over time, and this difference was significant at one year of follow-up $(p=0.018)$. The eyes with the worst initial VA tended to keep lower VAs, although these results were not statistically significant (Table 2).

\section{AGE}

The average age of the patients was $76.75 \pm 0.73$ years (95\% Cl: $75.28-78.22)$. The data show a loss of 22.33 letters (SD, 5.52) and 31.83 letters (SD, 5.80) in cases with an age $\geq 75$ years $(n=30)$ at 3 and 5 years of follow-up, respectively. For patients $<75$ years $(n=18)$, VA loss was of 7.78 letters $(S D, 5.40)$ and 20.28 letters (SD, 6.33) at 3 and 5 years of follow-up, respectively (Fig. 1). The progression of the neovascular process was more torpid in older patients. However, these differences were only statistically significant at 3 years of follow-up $(p=0.020)$ (Table 2$)$.

\section{SeX}

$39.6 \%$ were male and $60.4 \%$ female. In male patients, a loss of 24.47 letters (SD, 7.14) was observed at 3 years and of 32.37 letters (SD, 6.95) at 5 years, while in females, the loss was of 11.90 letters (SD, 4.78) and 24.31 letters (SD, 5.63) at 3 and 5 years of follow-up, respectively (Fig. 1). Female sex showed a strong tendency to maintain a higher VA over time, but these differences were not statistically significant (Table 2).

\section{Affected eye}

$56.3 \%$ of cases corresponded to the first eye with the onset of choroidal neovascularization and $43.7 \%$ of cases were the second eye affected (Fig. 1). Comparing the two groups, there were no statistically significant visual differences in any of the time points assessed (Table 2).

\section{LENS BIOMICROSCOPY}

Phakic eyes $(n=34)$ showed a loss of 10.29 letters (SD, 4.22) and of 18.97 letters (SD, 4.56), and pseudophakic eyes ( $n=13)$ showed a loss of 36.54 letters (SD, 8.13 ) and 53.08 letters (SD, 6.64) at 3 and 5 years of follow-up, respectively (Fig. 1). It was observed that pseudophakic eyes experienced a worse and significant visual evolution than those with an intact lens (Table 2).

\section{Discussion}

The indication for anti-VEGF therapy in patients with exudative AMD is supported by clinical trials conducted in 2005 and 2006, which demonstrated the improvement of VA in patients with AMD treated with ranibizumab compared to controls or photodynamic therapy ${ }^{3,4}$. 


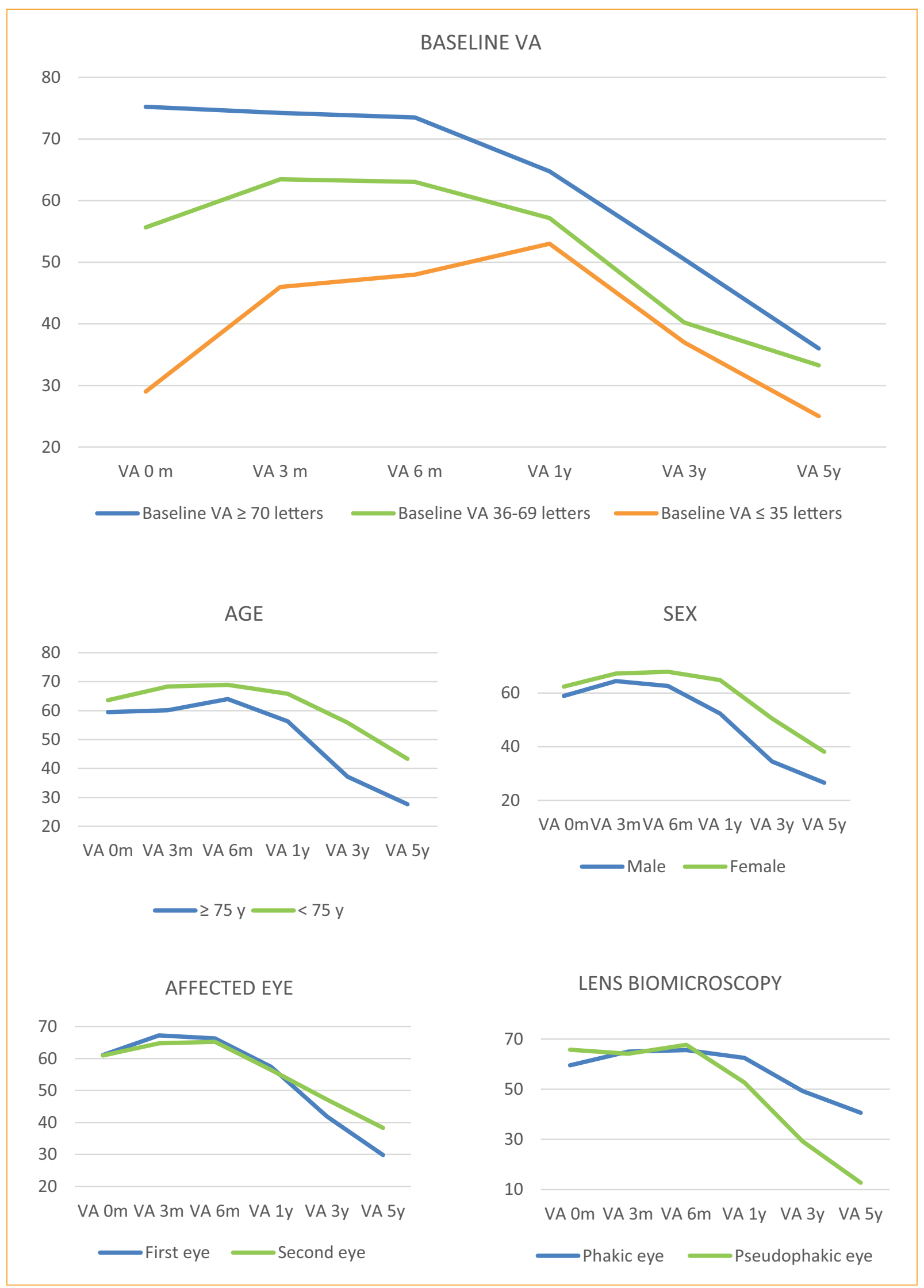

Figure 1. Graphic representation of the evolution of visual acuity (VA) over time for eyes with age-related exudative macular degeneration treated with intravitreal antiangiogenic drugs, according to the different clinical variables. 
Table 1. Mean number and standard deviation of intravitreal antiangiogenic injections and medical visits per year during a 5-year follow-up period

\begin{tabular}{|l|c|c|c|c|c|} 
& $1^{\text {st }}$ year & $2^{\text {nd }}$ year & $3^{\text {rd }}$ year & $4^{\text {th }}$ year & $5^{\text {th }}$ year \\
\hline No. injections/ & $4.81 \pm$ & $2.21 \pm$ & $1.73 \pm$ & $1.17 \pm$ & $0.9 \pm$ \\
\hline year & 0.16 & 0.23 & 0.25 & 0.23 & 0.21 \\
\hline No. visits/year & $7.19 \pm$ & 4.88 & $4.02 \pm$ & $3.40 \pm$ & $2.85 \pm$ \\
& 0.23 & \pm 0.26 & 0.22 & 0.25 & 0.25 \\
\hline
\end{tabular}

Subsequently, several publications documented the results of antiangiogenic therapy in the first two years of treatment; however, there is little information on the effectiveness of this treatment after 4 years of follow-up, and even more so if the information refers to the results derived from actual clinical practice.

Our data on the effectiveness of anti-VEGF treatment in AMD differ from previous studies, the results of which show maintenance or a discrete gain of VA over time. The gain or loss of letters should be interpreted according to initial VA, since subjects with better VA at diagnosis are less likely to gain vision than those who start with a poor VA, due to the "ceiling effect" (Fig. 1). Therefore, these observed differences could be influenced by the higher initial mean VA of our study compared to previous studies (Table 3).

It should also be considered that antiangiogenic treatment protocols in studies such as MARINA, ANCHOR and CATT, were based on rigid and well-defined criteria with monthly fixed injections or a PRN regimen (PrONTO and CATT) that differ from those used in clinical practice.

When we compare retrospective studies of a similar design, but with a longer follow-up, our results are unfavorable. The more representative are SEVEN UP'15, which prolonged the follow-up of patients included in the ANCHOR, MARINA and HORIZON trials, and the CATT Study Follow ${ }^{16}$, with 5 years of follow-up of the patients enrolled in the CATT trial. The positive balance favoring these studies may reflect the high degree of follow-up and treatment of the neovascular process during the first two years when they participated in the pivotal studies.

Furthermore, all these studies had sample losses, mainly due to lack of efficacy of the antiangiogenic treatment, and these patients were not included in the evaluation of long-term therapeutic effectiveness. Therefore, the good results obtained may be related to this percentage of patients lost to follow-up. In contrast, in our study, all patients completed a 5-year follow-up, regardless of having decided not to continue treatment due to the development of geographic atrophy or a disciform scar.
Significant VA gains may be of little relevance if the end result is poor vision that prevents the patient from performing activities of daily living. For this reason, it would be better to assess the efficacy of the treatment in terms of maintaining visual function. In previous studies, the percentage of eyes reading $>70$ letters increased at the end of the follow-up period. In our study, the proportion of eyes with initial VA $\geq 70$ letters (41.7\%) decreased over time, reducing by half $(22.92 \%)$ at 3 years, and represented $10.42 \%$ of cases at the end of the study (Table 4). Again, we consider that this disparity of results is due to the design of the study that included all patients during a 5-year follow-up, regardless of the efficacy of the treatment.

Despite these results, the behavior of VA over time coincides with previous studies; cases with poor baseline VA experience an improvement in the short term and eyes with a greater initial VA, show a lower initial net gain due to the "ceiling effect".

In our study, cases that preserved VA (loss $<15$ letters) at 3 years were half $(50 \%)$ and a third $(33.3 \%)$ at 5 years. These results are markedly lower compared to the MARINA and ANCHOR results, where visual stability was achieved in $95 \%$ of cases at one year of follow-up, and the SEVEN UP study, with a percentage of $66 \%$ after 7 years of follow-up. On the other hand, not all patients progressively lost vision, but 14.6 and $12.5 \%$ experienced a gain $>15$ letters at 3 and 5 years of follow-up, respectively.

In this study, the number of annual visits was less than in previous studies, which documented 7-9 visits in each year of follow-up. This is justified because, in many of our patients, the number of medical examinations was progressively spaced up to a minimum of two visits per year, since the eyes in more advanced stages have a very low VA due to the development of geographic atrophy or a disciform scar, and as the response to the pharmacological treatment is scarce or null, they do not require such an exhaustive follow-up. Similarly, the average number of injections in each year of follow-up was less than that administered in recently published studies ${ }^{20}$. This may be due to the fact that the clinical approach of the patients included in this study was prior to the publication of the current treatment protocols, which could determine that the disease was treated less aggressively.

The results of the influence of different clinical variables on VA values collected in this study are consistent with previous studies: patients $>75$ years have a more accelerated course of the neovascular process $^{21,22 ;}$ VA changes over time are not influenced by 
Table 2. Bivariate analysis (non-parametric Mann-Whithney $\mathrm{U}$ test) of visual results according to different clinical variables

\begin{tabular}{|c|c|c|c|c|c|c|c|}
\hline \multicolumn{3}{|c|}{ Baseline visual acuity } & \multirow[t]{2}{*}{ p-value } & \multicolumn{3}{|c|}{ Age } & \multirow[t]{2}{*}{ p-value } \\
\hline & $<70$ letters & $\geq 70$ letters & & & $<75$ years & $\geq 75$ years & \\
\hline 1 year & $56.43 \pm 19.57$ & $64.75 \pm 21.85$ & $0.018^{* *}$ & 1 year & $65.83 \pm 19.65$ & $56.33 \pm 20.88$ & $0.058^{*}$ \\
\hline 3 years & $39.64 \pm 25.85$ & $50.50 \pm 27.81$ & 0.118 & 3 years & $55.83 \pm 22.44$ & $37.17 \pm 27.31$ & $0.020^{* *}$ \\
\hline \multirow[t]{3}{*}{5 years } & $31.79 \pm 24.54$ & $36.00 \pm 30.59$ & 0.624 & 5 years & $43.33 \pm 23.94$ & $27.67 \pm 27.54$ & $0,052^{*}$ \\
\hline & \multirow[t]{2}{*}{$\leq 35$ letters } & \multirow[t]{2}{*}{$<35$ letters } & & \multicolumn{3}{|c|}{ Sex } & \multirow[t]{2}{*}{ p-value } \\
\hline & & & & & Male & Female & \\
\hline 1 year & $53.00 \pm 10.95$ & $60.70 \pm 21.54$ & $0.062^{*}$ & 1 year & $52.37 \pm 27.05$ & $64.83 \pm 13.72$ & 0.211 \\
\hline 3 years & $37.00 \pm 14.41$ & $45.00 \pm 28.03$ & 0.275 & 3 years & $34.47 \pm 27.93$ & $50.53 \pm 24.73$ & $0.055^{*}$ \\
\hline 5 years & $25.00 \pm 15.41$ & $34.53 \pm 27.98$ & 0.449 & 5 years & $26.58 \pm 22.80$ & $38.10 \pm 28.89$ & 0.179 \\
\hline \multicolumn{3}{|c|}{ Affected eye } & \multirow[t]{2}{*}{ p-value } & & \multicolumn{2}{|c|}{ Lens biomicroscopy } & \multirow[t]{2}{*}{ p-value } \\
\hline & First & Second & & & Phakic & Pseudophakic & \\
\hline 1 year & $57.41 \pm 24.47$ & $63.10 \pm 14.62$ & 0.842 & 1 year & $62.50 \pm 18.76$ & $52.69 \pm 25.30$ & 0.244 \\
\hline 3 years & $41.85 \pm 29.91$ & $47.14 \pm 22.94$ & 0.706 & 3 years & $49.26 \pm 23.90$ & $29.23 \pm 30.34$ & $0.048^{* *}$ \\
\hline 5 years & $29.81 \pm 28.54$ & $38.33 \pm 24.72$ & 0.266 & 5 years & $40.59 \pm 24.33$ & $12.69 \pm 23.06$ & $0.001^{* *}$ \\
\hline
\end{tabular}

* Values very close to $p<0.05$

** Statistical significance.

Table 3. Baseline visual acuity and visual results observed in different studies after one year of follow-up

\begin{tabular}{l|c|c|}
\hline Study & Baseline mean VA & $\begin{array}{c}\text { Mean balance after 1 year } \\
\text { of follow-up }\end{array}$ \\
\hline ANCHOR $^{4}$ & 47.1 & +11.3 \\
MARINA $^{3}$ & 53.7 & +7.2 \\
PrONTO $^{8}$ & 56.2 & +9.3 \\
CATT $^{5}$ & 61.5 & +6.4 \\
Our study & 61.0 & -1.14
\end{tabular}

gender differences ${ }^{21,22 ;}$ and the second eyes maintain a higher VA than the first eyes at all follow-up time points, although this is not significant ${ }^{17,23,24}$.

Finally, we observed that, even with a higher initial VA in pseudophakic eyes, these experienced a more marked visual deterioration, three times greater compared to phakic eyes, despite the visual limitations secondary to the presence of an advanced cataract, typical of an aging population. Our data contrast with previous studies that did not find statistically significant differences between these two groups ${ }^{25-27}$, although it is true that some of them suggest that phakic eyes tend to show less VA loss. To explain these differences, it has been hypothesized that cataract surgery could alter the pharmacodynamics and/or pharmacokinetics of the drug released in the vitreous cavity. On one hand, changes in the protein composition of the vitreous have been described, as well as a higher incidence of posterior vitreous detachment after surgery, which could influence the half-life of the drug. On the other hand, pseudophakic eyes could favor the clearance of the drug through the aqueous humor elimination pathways in the anterior chamber ${ }^{28}$.

\section{Conclusions}

Current evidence shows the need for a minimum of seven injections in the first year of treatment. Our study was conducted in a period in which the stability of the lesion was not clearly defined based on the protocol used (monthly, PRN, T\&E), so our patients probably were under-treated in the evaluation period. Visual results could also be influenced by including eyes in the VA analysis with geographic atrophy or disciform scars.

\section{Conflicts of interest}

The authors declare no conflicts of interest. 
Table 4. Proportion of cases with good visual function ( $\geq 70$ letters) at the beginning and at the end of different studies, during different follow-up periods

\begin{tabular}{|l|c|c|c|}
\hline Study & Initial percentage $\geq 70$ letters & Final percentage $\geq 70$ letters & Data collection time \\
\hline $\begin{array}{l}\text { Talks, et al. }{ }^{17} \\
\text { Writing Committee for the UK Age-Related } \\
\text { Macular Degeneration EMR Users Group }\end{array}{ }^{18}$ & 16.4 & 33.7 & 1 year \\
\hline Gillies, et al. ${ }^{19}$ & 16 & 30 & 1 year \\
\hline CATT Study Follow ${ }^{16}$ & 23 & 29 & 3 years \\
\hline SEVEN UP15 & 37.5 & 37 & 3 years \\
\hline Our study & 23 & 49.6 & 5 years \\
& 41.7 & 37 & 7 years \\
\hline
\end{tabular}

\section{Ethical disclosures}

Protection of human and animal subjects. The authors declare that no experiments were performed on humans or animals for this study.

Confidentiality of data. The authors declare that they have followed the protocols of their work center on the publication of patient data.

Right to privacy and informed consent. The authors declare that no patient data appear in this article, as it is retrospective.

\section{References}

1. Ferris FL, Wilkinson $\mathrm{CP}$, Bird A, Chakravarthy U, Chew E, Csaky K, et al. Clinical Classification of Age-related Macular Degeneration. Ophthalmology. 2013;120:844-51

2. Mordenti J, Cuthbertson RA, Ferrara N, Thomsen K, Berleau L, Licko V, et al. Comparisons of the intraocular tissue distribution, pharmacokinetics, and safety of 125I-labeled full-length and Fab antibodies in rhesus monkeys following intravitreal administration. Toxicol Pathol. 1999;27:536-44.

3. Rosenfield PJ, Brown DM, Heier JS, et al. Ranibizumab for neovascular age-related macular degeneration. N Engl J Med. 2006;355:1419-31.

4. Brown DM, Kaiser PK, Michels M, Soubrane G, Heier JS, Kim RY, et al. Ranibizumab versus verteporfin for neovascular age-related macular degeneration. N Engl J Med. 2006;355:1432-44.

5. The CATT Research Group. Ranibizumab and bevacizumab for neovascular age-related macular degeneration. N Engl J Med 2011; 364: 1897-908.

6. Regillo CD, Brown DM, Abraham P, Yue H, lanchulev T, Schneider S, et al. Randomized, double-masked, sham-controlled trial of ranibizumab for neovascular age-related macular degeneration: PIER Study year 1 . Am J Ophthalmol. 2008; 145:239-48.

7. Schmidt-Erfurth U, Eldem B, Guymer R, Korobelnik JF, Schlingemann RO, Axer-Siegel R, et al. Efficacy and safety of monthly versus quarterly ranibizumab treatment in neovascular age-related macular degeneration: the EXCITE study. Ophthalmology. 2011;118:831-9.

8. Fung AE, Lalwani GA, Rosenfeld PJ, Dubovy SR, Michels S, Feuer WJ, et al. An Optical Coherence Tomography-Guided, Variable Dosing Regimen with Intravitreal Ranibizumab (Lucentis) for Neovascular Age-Related Macular Degeneration. Am J Ophthalmol. 2007;143:566-83.

9. Boyer DS, Heier JS, Brown DM, Francom SF, lanchulev T, Rubio RG. A Phase IIlb study to evaluate the safety of ranibizumab in subjects with neovascular age-related macular degeneration. Ophthalmology. 2009; 116:1731-9.

10. Sadda SR. HORIZON extension trial of ranibizumab [LUCENTIS $®$ ] for neovascular agerelated macular degeneration [AMD]: first-year safety and efficacy results. Retina Society Annual Meeting. Scottsdale, USA, 2008.
11. Holz FG, Amoaku W, Donate J, Guymer RH, Kellner U, Schlingemann RO, et al. Safety and efficacy of a flexible dosing regimen of ranibizumab in neovascular age-related macular degeneration: the SUSTAIN study. Ophthalmology. 2011; 118:663-71.

12. Spaide R. Ranibizumab according to need: a treatment for age-related macular degeneration. Am J Ophthalmol. 2007; 143:679-80.

13. Browning DJ, Kaiser PK, Rosenfeld PJ, Stewart MW. Aflibercept for age-related macular degeneration: a game-changer or quiet addition? Am J Ophthalmol. 2012:154:222-6

14. Stewart MW. Clinical and differential utility of VEGF inhibitors in wet age-related macular degeneration: focus on aflibercept. Clin Ophthalmol. 2012;6:1175-186.

15. Rofagha S, Bhisitkul RB, Boyer DS, Sadda SR, Zhang K, SevenUp Study Group. Seven-year outcomes in ranibizumab-treated patients in ANCHOR, MARINA and HORIZON: a multicenter cohort study (SEVEN-UP). Ophthalmology 2013;120(11):2292-9.

16. Comparison of Age-Related Macular Degeneration Treatment Trials (CATT) Research Group. Five-Year Outcomes with Anti-Vascular Endothelial Growth Factor Treatment of Neovascular Age-Related Macular Degeneration. Ophthalmology. 2016;123:1751-61.

17. Talks JS, Lotery AJ, Ghanchi F, Sivaprasad S, Johnston RL, Patel N, et al. First-Year Visual Acuity Outcomes of Providing Aflibercept According to de VIEW Study Protocol for Age-Related Macular Degeneration. Ophthalmology. 2016;123:337-43.

18. Committee for de UK Age-Related Macular Degeneration EMR Users Group. The neovascular age-related macular degeneration database: a multicenter study of 92976 ranibizumab injections: report 1: visual acuity. Ophthalmology. 2014;121:1092-101.

19. Gilles MC, Campain A, Barthelmes D, Simpson JM, Arnold JJ, Guymer RH, et al. Long-Term Outcomes of Treatment of Neovascular Age-Related Macular Degeneration. Ophthalmology. 2015;122:1837-45.

20. Gemenetzi M and Patel PJ. A Systematic Review of the Treat and Extend Treatment Regimen with Anti-VEGF Agents for Neovascular Age-Related Macular Degeneration. Ophthalmol Ther. 2107:6:79-92.

21. Kaiser PK, Brown DM, Zhang K, Hudson HL, Holz FG, Shapiro H, et al. Ranibizumab for predominantly classic neovascular age-related macular degeneration: subgroup analysis of first-year ANCHOR results. Am J Ophthalmol. 2007:144(6):850-7

22. Boyer DS, Antoszyk AN, Awh CC, Bhisitkul RB, Shapiro H, Acharya NR, et al. MARINA Study Group. Subgroup analysis of the MARINA study of ranibizumab in neovascular age-related macular degeneration. Ophthalmology. 2007;114:246-52.

23. Zarranz-Ventura J, Liew G, Johnson RL, Xing W, Akerele T, McKibbin M, et al. The Neovascular Age-Related Macular Degeneration Database. Report 2: Incidence, Management, and Visual Outcomes of Second Treated Eyes. Ophthalmology. 2014; 121:1966-75.

24. Eldaly MA, Styles C. First versus second eye intravitreal ranibizumab therapy for wet AMD. Retina. 2009:29:325-8.

25. Weinberg DV, Shapiro H, Ehrlich J. Ranibizumab Treatment Outcome in Phakic versus Pseudophakic Eyes. An individual Patient Data Analysis of 2 Phase 3 Trials. Ophthalmology. 2013:120:1278-82.

26. Baek JS, Cho HJ, Cho SW, Kim CG, Kim JW. Intravitreal ranibizumab injection for neovascular age-related macular degeneration in phakic versus pseudophakic eyes. Retina. 2013;33:467-73.

27. Ozkaya A, Alkin Z, Yazici A, Demirok A. Comparison of intravitreal ranibizumab in phakic and pseudophakic neovascular age-related macular degeneration patients with good baseline visual acuity. Retina. 2014;34:853-9. 